ఠ

\title{
Role of digoxin in controlling the ventricular rate during atrial fibrillation: a systematic review and a rethinking
}

REVIEW

This article was published in the following Dove Press journal:

Research Reports in Clinical Cardiology

7 May 2014

Number of times this article has been viewed

\author{
Philippe Maury' \\ Anne Rollin' \\ Michel Galinier' \\ Yves Juillière ${ }^{2}$ \\ 'University Hospital Rangueil, \\ Toulouse, France; ${ }^{2}$ Institut Lorrain \\ du Coeur de des Vaisseaux Louis \\ Mathieu, Nancy, France
}

Correspondence: Philippe Maury Cardiology, University Hospital Rangueil, 31059 Toulouse Cedex 09, France Tel +33561323054 Fax +33561322246 Email mauryjphil@hotmail.com

\begin{abstract}
Although digitalis has been used since the last century, it seems to be in the process of being progressively abandoned. However, digoxin has demonstrated a large positive benefit in terms of reduction of morbidity in heart failure patients with sinus rhythm, while the sometimesobserved increase in mortality is dramatically reduced with low serum concentrations. Digoxin, which is the only digitalis currently available, remains one of three drugs used for rate control in atrial fibrillation. Even if digoxin alone is insufficient to provide rate control during exertion in most patients, the optimal cardiac rate both at rest and at exertion is still undetermined, as is the importance of achieving sufficient rate control in asymptomatic patients. Because of its low cost and the accumulated knowledge and expertise about prescription, digoxin probably will remain an undisputed medication for rate control for atrial fibrillation, especially for heart failure patients.
\end{abstract}

Keywords: digitalis, heart failure, atrial fibrillation, heart rate

\section{Introduction}

Digitalis' first use can be traced back to 2 centuries ago, in 1785, when William Withering described the properties of the leaves of the common foxglove plant Digitalis purpurea. ${ }^{1}$ However, after an enormous amount of use in treating heart failure, digoxin, which seems to be the last digitalis product available on the world market for medical purpose, is on the way to being filed under "endangered drugs" because of the discovery of other powerful agents for treating heart failure patients. Digoxin is, however, still widely used for controlling the heart rate during AF. In this article, we present an overview of the current and future roles of digoxin in AF.

\section{Cellular, neurohormonal, and electrophysiological properties of digoxin}

Many cardiovascular effects of digoxin have been reported, and most, if not all, are directly or indirectly related to the inhibition of sodium-potassium adenosine triphosphatase (Na-K ATPase) activity.

The inotropic properties of digoxin are the foundation for the role of this medication in heart failure. These properties seem mainly to be a result of the inhibition of Na-K ATPase activity of the myocardial cells, leading to cellular sodium overload and then to an increase in sarcoplasmic calcium content mediated by the $\mathrm{Na} / \mathrm{Ca}$ exchanger. Such a higher calcium loading is clearly related to a higher calcium induced-calcium release and to stronger myocardial contractility. ${ }^{2}$ Activation of the $\mathrm{Na} / \mathrm{Ca}$ exchanger itself is, however, not powerful enough to achieve therapeutic or toxic intracellular lev- 
els of calcium. A newly described mechanism is that digoxin further acts at nanomolar concentrations via inhibition of the cardiac potassium HeRG (human ether-a-go-go-related gene) channel via trafficking inhibition, thereby promoting inotropic effects and arrhythmias. ${ }^{3,4}$

Apart from these inotropic properties, digoxin also has renal effects, including diuretic and natriuretic actions independent of cardiac hemodynamics, as well as inhibition of the renin activation. ${ }^{5}$ Digoxin also has demonstrated direct vasoconstrictive arterial and venous effects. ${ }^{6}$

A stimulating central effect on both the sympathetic tone ${ }^{7}$ and the parasympathetic tone has also been noted, ${ }^{8}$ with the latter being responsible for chronotropic and dromotropic effects. Improvement in the neurohormonal profile of heart failure patients has been achieved with low doses and low serum digoxin concentrations, possibly related to digoxin modulating effects on various neurohormonal abnormalities, including improvement on baroreceptor function, a vagomimetic effect, a sympathoinhibitory effect, a decrease in circulating neurohormones with dose-related effects on neurohormones, and antifibrotic effects. ${ }^{9}$ Sensitization of the sympathetic afferent pathways involved in control of arterial pressure by digoxin leads to an inhibition of the peripheral sympathetic tone (and an associated increase in central vagal tone), leading to hypotension and bradycardia. ${ }^{10-13}$ Digoxin also sensitizes vagal afferents mediating the cardiopulmonary baroreflex influence on renal nerve activity. ${ }^{10}$ In addition, there is some attenuation of the carotid sinus baroreceptor discharge sensitivity in heart failure, and some data are consistent with an augmentation of $\mathrm{Na} / \mathrm{K}$-ATPase activity in the carotid sinus baroreceptor. ${ }^{12}$ Digoxin can directly increase the sensitivity of altered baroreceptors and produce significant changes in carotid sinus nerve activity and cardiovascular function. ${ }^{11}$ The bradycardic and hypotensive effect of baroreceptor stimulation increased significantly after digoxin. ${ }^{13}$ Plasma norepinephrine decreased, high-frequency power increased, and the root mean square of successive differences in RR interval increased during digoxin treatment, indicating a substantial increase in parasympathetic activity, whereas low-frequency power, an index of baroreflex activity, was also significantly increased by digoxin therapy, indicating that long-term therapy with digoxin acts to ameliorate the autonomic dysfunction of patients with heart failure and that the short-term neurohormonal effects of digoxin are sustained during prolonged treatment with the drug. ${ }^{14}$ The role of stimulation of the altered baroreflex by digoxin is thought to play a major role in the treatment of heart failure. Moreover, the increase in ventricular contractility may further lead to a decrease in sympathetic tone because of the relief of congestive heart failure. Mechanisms of action of digoxin are shown in Figure 1.

The effects of digoxin differ on the sinus node, atrioventricular node, and atrial tissues and are less pronounced on ventricular tissues. These effects are a combination of minor direct and major neurovegetative-mediated effects, mainly seen after an increase in the vagal tone. Digoxin has a negative chronotropic action on the sinus node and decreases the cardiac rate, especially in patients with heart failure. At the atrial level, digoxin slightly decreases the action potential duration, and thus the refractory periods and the conduction velocities in case of heart failure, but does not seem to have any significant antiarrhythmic effect on atrial arrhythmias. Finally, digoxin has a negative dromotropic effect on the

\title{
Inhibition of Na-K ATPase
}

Higher calcium cellular loading

Increased sensitivity of baroreceptors

Increase in parasympathetic activity

\section{Sensitization of the sympathetic and vagal afferent pathways}

\section{Stimulating central effect on the sympathetic and parasympathetic tone}

\author{
Diuretic action
}

Arterial and venous vascoconstriction

Figure I Mechanisms of action of digoxin

Abbreviation: Na-K ATPase, sodium-potassium adenosine triphosphatase. 
atrioventricular node, leading to an increase in refractory periods and nodal conduction time. ${ }^{15,16}$ During AF, the ventricular rate is mainly dependent on the properties of the atrioventricular node, which are influenced by drugs, the neurovegetative tone, and the rate and regularity of atrial depolarizations. Therefore, digoxin decreases the cardiac rate during $\mathrm{AF}$, especially in cases of heart failure, because of its negative dromotropic effect on the atrioventricular node and because of an increase in the atrial rate, leading to more concealed conduction into the atrioventricular node. ${ }^{16}$ However, this action is only significant at rest and is far less present at exertion, when the sympathetic tone is dominant. In patients with $\mathrm{AF}$ and heart failure, the decrease in cardiac rate may increase cardiac output, which in turn may further decrease sympathetic tone. Electrophysiological actions of digoxin at different levels are depicted in Table 1.

\section{Digoxin and heart failure in sinus rhythm}

The use of digoxin in patients with congestive heart failure and with sinus rhythm has been a matter of debate, even it had been long recognized that some heart failure patients did improve clinically with digoxin treatment. From 1993 to 1997, the Prospective Randomized study Of Ventricular failure and the Efficacy of Digoxin (PROVED), Randomized Assessment of Digoxin on Inhibitors of Angiotensin-Converting Enzyme (RADIANCE), and Digitalis Investigation Group (DIG) trials demonstrated clinical and left ventricular function improvements with digoxin in mild to moderate heart failure in patients in the sinus rhythm, without any detrimental or positive effect on survival, especially in patients with mild heart failure. ${ }^{17-20}$ In patients with severe heart failure and sinus rhythm, digoxin also demonstrated a significant reduc-

Table I Electrophysiological actions of digoxin

\section{Sinus node}

(minor direct and major neurovegetative mediated effects)

Negative chronotropic effect

Decrease in sinus node heart rate

Atrium

Discrete decrease in refractory periods and conduction velocity

No significant antiarrhythmic property

Atrioventricular node

(minor direct and major neurovegetative-mediated effects)

Negative dromotropic effect

(increase in conduction time and refractory periods)

Ventricles

Decrease in action potential duration (shortening of QT interval) No other significant electrophysiological property for dosing in the therapeutic range tion in the risk of the 2-year composite endpoint of heart failure mortality and hospitalizations. ${ }^{21}$ In a subset of the DIG trial, digoxin was associated with long-term improvement in kidney function in $15 \%$ of patients, leading to a reduction in death or hospitalization. ${ }^{22}$ One should acknowledge, however, that currently considered optimal therapy (angiotensin-converting-enzyme inhibitors and beta-blockers) was not available or was poorly prescribed at this time.

However, on DIG post hoc analysis, digoxin therapy was associated with an increased risk of death from any cause among women (but not men), ${ }^{23}$ but a decreased mortality for concentrations lower than $1 \mathrm{ng} / \mathrm{mL} \cdot{ }^{24}$ Mortality and morbidity also have been shown to be increased after the use of digoxin when prescribed in the elderly. ${ }^{25}$ More recent comparative data prove, in fact, that the effects of digoxin on morbidity and mortality are similar to those of ivabradin ${ }^{26}$ because of the pivotal role of a low cardiac rate in patients with heart failure. Finally, some recent works argue against any detrimental role of digoxin in heart failure and even demonstrate a favorable profile of the drug on mortality ${ }^{27,28}$ (but AF was present in some of the studied patients), whereas digoxin use was associated with a higher mortality in other works. ${ }^{29,30}$ However, in one of these studies, ${ }^{29}$ mean serum digoxin concentration was $1.02 \mathrm{ng} / \mathrm{mL}$, thereby suggesting too high a level was prescribed in many patients. In a very recent study of systolic heart failure patients, a discharge prescription of digoxin was associated with lower all-cause hospital readmission, without higher mortality, but only in those patients with an ejection fraction lower than $45 \%{ }^{31}$

There have also been many controversies about the risk of digoxin in patients with ischemic heart disease. An early retrospective study already suggested that digoxin increased the early mortality of myocardial infarction patients with congestive heart failure and complex ventricular premature beats. ${ }^{32}$ However, digoxin was not an independent risk factor contributing significantly to mortality in patients with coronary artery disease according to the Coronary Artery Surgery Study (CASS) Registry. ${ }^{33}$ Compared with captopril, digoxin improves general well-being and symptoms, whereas worsening of angina is more frequent with captopril compared with digoxin in patients with ischemic heart disease. ${ }^{34}$ However, cardiovascular events are lower with captopril compared with digoxin. ${ }^{34}$ As a result of many other studies in that area, it has finally been accepted that digoxin is not harmful in coronary artery disease patients with heart failure.

As a result of all these data, current guidelines for heart failure $^{35}$ do not recommend digoxin as a primary medication in patients in sinus rhythm, despite the lack of harmful 
effect and the recognized positive actions on morbidity. No new trial has been planned since then, probably because of the lack of interest from the pharmacological industry in this old and generic drug, avoiding any oncoming change in the guidelines.

\section{Digoxin in patients with AF}

A completely different situation happens in the case of AF. Whether the patient presents with heart failure or not, AF may be still an indication for digoxin. It was recognized early on that discontinuation of digoxin may induce clinical worsening of congestive symptoms in heart failure patients with AF. However, it should be acknowledged that data on the use of digoxin in AF patients are limited because the main prospective randomized controlled trials with digoxin were performed in patients with heart failure and sinus rhythm, whereas such trials are still not available for patients with AF.

In the Stroke Prevention Using Oral Thrombin Inhibitor in Atrial Fibrillation (SPORTIF) III and V trials, AF patients taking digoxin were seen to have a higher mortality $(4.22 \%$ / patient-year compared with $2.66 \%$ /patient-year), and this persisted after multivariate risk factor adjustment (hazard ratio [HR], 1.53). ${ }^{36}$ The increased mortality rate linked to digoxin was found to be even larger in patients with heart failure. ${ }^{37}$

The Atrial Fibrillation Follow-Up Investigation of Rhythm Management (AFFIRM) trial was dedicated to compare "rate" versus "rhythm" control in patients with paroxysmal or persistent $\mathrm{AF}^{38}$ Digoxin was linked to a poorer survival in AFFIRM, ${ }^{39}$ but this was initially perceived as representing the prescription of digoxin for patients at greater risk of death, such as those with heart failure, rather than reflecting a deleterious effect of digoxin on survival. Recent post hoc analysis of this trial concluded there was no evidence of increased mortality or hospitalization in those taking digoxin as baseline initial therapy. ${ }^{40}$ However, data from the same population in another post hoc analysis revealed that digoxin was associated with an increase in allcause mortality (HR, $1.41 ; P<0.001)$ (whatever the sex), cardiovascular mortality (HR, $1.35 ; P=0.016)$, and arrhythmic mortality (HR, $1.61 ; P=0.009)$, and that all-cause mortality was increased with digoxin in patients without (HR, 1.37; $P=0.019)$ or with (HR, $1.41 ; P=0.01)$ heart failure. ${ }^{41}$ Similar observations were made when restricted to patients randomized to the rate control-only cohort (HR, 1.46 [95\% confidence interval, 1.13-1.90]; $P=0.004$ ).

Such diverging results from the same population are difficult to explain. One explanation is that high serum levels were encouraged in the AFFIRM protocol $(\geq 1.0 \mathrm{ng} / \mathrm{mL})$, which has been shown to lead to an increased mortality. ${ }^{24}$ Moreover, many patients were excluded because of missing data; these are not prospective trials, and many important parameters such as cardiomyopathy, symptoms of AF, renal failure, degree of heart failure, and failure of antiarrhythmic drugs were different or not indicated for patients on and off digoxin. Finally, digoxin use was assessed at a fixed time of initial therapy at randomization in one study ${ }^{40}$ while being treated as a time-dependent covariate, accounting for changes in digoxin use over time, in the other one. ${ }^{41}$ Of note is that similar post hoc analysis for the Atrial Fibrillation and Congestive Heart Failure (AF-CHF) Trial, in which around $65 \%$ of patients in both the rate and rhythm control groups were given digoxin, is not available. ${ }^{42}$ Other recent studies argue against any detrimental independent role of digoxin on mortality and hospitalizations in AF patients ${ }^{43}$ or even show that rehospitalization in heart failure patients with AF is decreased in those taking digoxin. ${ }^{31}$

A summary of the role of digoxin in patients with sinus rhythm versus AF is shown in Table 2.

\section{Clinical role of digoxin in AF}

Digoxin is used to control heart rate in $35 \%-70 \%$ of patients with $\mathrm{AF}^{44}$ According to the AF guidelines, because of its properties on the atrioventricular node, digoxin is one of the main drugs used for controlling the ventricular rate in AF. The main goal is to maintain the cardiac rate into appropriate limits, both at rest and during exertion or stress. Excessive cardiac rates may lead to palpitations, dizziness, and discomfort or to dyspnea and congestive heart failure, even in cases of preserved left ventricular systolic function, mainly because of altered filling resulting from the decreased diastolic time and the loss of atrial contraction. When sustained for a long time, AF with inappropriately fast cardiac rates may lead to tachycardia-induced cardiomyopathy, a form of cardiomyopathy with reduced systolic function, characterized by its regression when the cardiac rate normalizes. AF-induced

Table 2 Digoxin in patients in sinus rhythm versus atrial fibrillation

\begin{tabular}{ll}
\hline Sinus rhythm & Atrial fibrillation \\
\hline $\begin{array}{l}\text { Clinical and left ventricular } \\
\text { function improvements }\end{array}$ & $\begin{array}{l}\text { No prospective trial; increase in } \\
\text { mortality or not, depending on the } \\
\text { post hoc analysis }\end{array}$ \\
$\begin{array}{l}\text { No detrimental effect on survival } \\
\text { Reduction in heart failure } \\
\text { mortality or hospitalizations }\end{array}$ \\
$\begin{array}{l}\text { No increase in mortality for } \\
\text { concentrations }<1 \mathrm{ng} / \mathrm{mL}\end{array}$ \\
\hline
\end{tabular}


tachycardia-induced cardiomyopathy is very frequent, even in case of associated heart disease, because maintenance of sinus rhythm in heart failure patients with AF may significantly increase the left ventricular ejection fraction, not only in patients without concurrent structural heart disease $(+24 \%)$ and those with inadequate rate control before ablation $(+23 \%)$ but also in those with coexisting heart disease $(+16 \%)$ and adequate rate control before ablation $(+17 \%) .{ }^{45}$ These changes are even substantially greater in patients with baseline more severe impairment of LV function. ${ }^{46}$ Deterioration of LV function appears to be related to both the cardiac rate and the duration of $\mathrm{AF}^{47,48}$ In addition, in patients with lone $\mathrm{AF}$, the rate control by ablation of the atrioventricular conduction may lead to an increase in LV ejection fraction and a decrease in LV-end-systolic and end-diastolic dimensions. ${ }^{47}$

If the clinical benefits of lowering heart rate by digoxin, especially for heart failure patients with AF, have already been proved, it is somewhat paradoxical to see that mortality seems to be increased in AF patients taking digoxin, at least in some works (see earlier text). Although a definitive answer to this dilemma will need additional prospective trials, one can, however, conclude that if harmful effects of digoxin in AF patients exist, they are probably of lower clinical relevance compared with the drug's clinical benefit, provided that doses are adapted and that clinical and biological monitoring is continued.

What is the optimal cardiac rate during AF? This issue does not seem to have been definitively assessed. The optimal level of heart rate control with respect to morbidity, mortality, quality of life, and symptoms remains unknown. The lower cardiac output resulting from loss of atrial contraction during AF should be corrected by an accelerated heart rate, which should not exceed certain limits. But what are these limits, both at rest and at exertion? Cardiac output was always found to be proportional to the heart rate when the ventricular rate was less than 90 beats per minute but was inversely proportional in around half the patients with a ventricular rate greater than 90 beats per minute, and always decreased for heart rates higher than 140 beats per minute. ${ }^{49}$ Because atrial contraction is thought to be responsible for $20 \%-50 \%$ of the stroke volume in sinus rhythm, the ventricular rate needs to be $20 \%-50 \%$ higher than in sinus rhythm to maintain normal cardiac output. ${ }^{49}$ In patients with AF (most receiving digoxin), the maximal heart rate during maximal exercise test exceeds the age-expected maximal heart rate by a mean of 20 beats per minute ( 50 beats per minute), although patients with lone AF demonstrated normal exercise capacity. ${ }^{50}$ This highlights the relative lack of clinical relevance of maximal heart rates during AF, at least for healthy hearts.
In the American College of Cardiology/American Heart Association/European Society of Cardiology Guidelines for the Management of Patients with Atrial Fibrillation from 2006, the criteria for rate control was to achieve ventricular rates between 60 and 80 beats per minute at rest and between 90 and 115 beats per minute during moderate exercise. ${ }^{51}$ This was mainly based on the results of the AFFIRM trial, in which adequate control was defined as an average heart rate up to 80 beats per minute at rest, and either an average rate up to 100 beats per minute over ambulatory Holter monitoring, with no rate above $100 \%$ of the maximum age-adjusted predicted exercise heart rate, or a maximum heart rate of 110 beats per minute during a 6-minute walk test. ${ }^{52}$ Higher resting heart rates were, however, not associated with an adverse prognosis. In the Rate Control versus Electrical Cardioversion (RACE) trial, rate control was defined as less than 100 beats per minute at rest. ${ }^{53}$ In the AF-CHF trial, rate control was to achieve a target heart rate of 80 beats per minute at rest or 110 beats per minute during a 6-minute walk test. ${ }^{42}$

However, more recent AF guidelines somewhat changed this perception. The RACE II trial did not identify a benefit of "stringent" rate control (resting heart rate, 80 beats per minute, and an adequate increase in heart rate on moderate exertion) over "lenient" rate control (resting heart rate of 110 beats per minute). ${ }^{54}$ Symptoms, adverse events, and quality of life were similar in both groups. A "lenient" rate control therapy approach was therefore considered reasonable in patients without severe symptoms because of a high ventricular rate. On this basis, both the 2010 European guidelines for the management of AF and the 2011 American College of Cardiology Foundation/American Heart Association/Heart Rhythm Society focused update suggest that an initially lenient rate control approach should be used, with dosing of rate control drugs being increased and drugs being combined until this target has been achieved..$^{55,56}$ If patients remain symptomatic, or in patients with altered ejection fraction, a stricter rate control target should be pursued (resting heart rate, 80 and 110 beats per minute during moderate exercise or during a 6-minute walk). ${ }^{55,56}$

\section{The role of digoxin in AF}

Rate control is achieved using pharmacological interventions in most of the patients with $\mathrm{AF}$, with only a minority requiring implantation of a pacemaker for symptomatic bradycardia ${ }^{52,55}$ or atrioventricular node ablation/modification. ${ }^{52}$ Digoxin, beta-blockers, and nondihydropyridine calcium channel antagonists are essentially used for that purpose. Because the 
main mechanism for dromotropic action of digoxin during AF relies on an increased vagal tone (see earlier text), the ability of digoxin to decrease heart rate during adrenergic drives is limited or even absent; thus, digoxin is effective for control of heart rate at rest, but not during exercise, although $70 \%$ of AFFIRM patients receiving digoxin alone were found to have rate control at exercise. ${ }^{52}$ Importantly, a satisfying resting heart rate under digoxin does absolutely not imply an adequate rate at exertion. Thus, beta-blockers or calcium channel antagonists are the preferred drugs, especially for patients without significantly depressed left ventricular systolic function, whereas the combination of a beta-blocker and digoxin may be beneficial in patients with heart failure. In the patients randomized to rate control in the AFFIRM trial, adequate rate control was achieved in $58 \%$ of patients with the first drug or combination $(70 \%$ with beta-blockers \pm digoxin, 54\% with calcium channel blockers \pm digoxin, and $58 \%$ with digoxin alone). ${ }^{42}$ Overall, digoxin was prescribed in $63 \%$ of patients (either as a sole drug or in combination) for adequate rate control. ${ }^{52}$ Rate control was achieved with digoxin alone in $54 \%$ of heart failure patients and in $71 \%$ of the other patients. ${ }^{52}$ In the AF-CHF trial, adequate rate control was achieved in $82 \%-88 \%$ of patients during the follow-up, using adjusted doses of beta-blockers with digoxin. ${ }^{42}$ Of note is that because no superiority of rhythm control over rate control was observed in this trial, it is tempting to conclude that the rate control was probably optimal with beta-blockers and digoxin in this population.

\section{Antiarrhythmic role of digoxin in AF}

Digoxin is devoid of any antiarrhythmic property and may even promote and lengthen the duration of paroxysmal episodes of AF because of the increase of vagal tone and the reduction of atrial refractory periods. ${ }^{57,58}$

\section{Potential hazards for prescribing digoxin in AF patients}

Digoxin has a narrow therapeutic margin and may induce potentially severe adverse effects. ${ }^{59,60}$ Bradycardia and gastrointestinal or neurological disorders are the early warning signs for digoxin toxicity, which could be detected by simple clinical monitoring; dosing is not always sufficient. Special care is required for patients with renal failure, elderly patients, and patients receiving potentially interacting drugs (see Table 3). ${ }^{59,60}$ As digoxin levels are mainly dependent on renal elimination, very special attention has to be given when it is prescribed to patients with altered renal functions, and reduced doses and careful clinical and biological monitoring are required.

Some extracardiac risks have been described when using digoxin, which should be known even if there is the probability of marginal relevance. Experimentally, increased intracellular calcium is a key event in platelet activation and endothelial cell function, and digoxin activates platelets in vitro, whereas endogenous digoxin-like substances affect biologic processes in endothelial cells. In fact, nonvalvular AF patients taking digoxin have increased levels of P-selectin (CD62P) expression in platelets and increased markers of endothelial activation, ${ }^{61}$ even if no greater risk for thromboembolism has been described using digoxin so far. Digoxin treatment has been linked with an increased incidence of breast cancer. ${ }^{62}$ Mortality is increased in hemodialysis patients taking digoxin, especially for high dosing and low potassium levels. ${ }^{63}$

Table 3 Digoxin and drug or ionic disturbance interactions

\begin{tabular}{|c|c|c|c|}
\hline $\begin{array}{l}\text { Drug and ionic } \\
\text { disturbances }\end{array}$ & Mechanism of interaction & Adverse effects & How to prevent \\
\hline Verapamil & Increases serum digoxin concentration & Digoxin toxicity & Reduce digoxin dosing \\
\hline $\begin{array}{l}\text { Amiodarone (high } \\
\text { dosing only) }\end{array}$ & Increases serum digoxin concentration & Digoxin toxicity & Reduce digoxin dosing \\
\hline Spironolactone & Increases serum digoxin concentration & Digoxin toxicity & Reduce digoxin dosing \\
\hline Quinidine & Increases serum digoxin concentration & Digoxin toxicity & Reduce digoxin dosing \\
\hline Propafenone & Increases serum digoxin concentration & Digoxin toxicity & Reduce digoxin dosing \\
\hline Hypokalemia & $\begin{array}{l}\text { Increases digoxin toxicity (increases } \\
\mathrm{Na}-\mathrm{K} \text { ATPase fixation of digoxin); } \\
\text { increases serum digoxin concentration }\end{array}$ & Digoxin toxicity & Control K level \\
\hline Hypercalcemia & Increases digoxin toxicity & Digoxin toxicity & Avoid Ca perfusion \\
\hline Diuretics & Hypokalemia & See hypokalemia & Control K level \\
\hline Warfarin & Increases serum digoxin concentration & Digoxin toxicity & Reduce digoxin dosing \\
\hline Cyclosporine & Increases serum digoxin concentration & Digoxin toxicity & Reduce digoxin dosing \\
\hline Macrolides & Increases serum digoxin concentration & Digoxin toxicity & Reduce digoxin dosing \\
\hline
\end{tabular}

Abbreviation: Na-K ATPase, sodium-potassium adenosine triphosphatase. 


\section{The future of digoxin}

In terms of heart failure with sinus rhythm, digoxin always presents a large positive benefit in morbidity reduction, which is one of the big deals for the future. The risk for major adverse effects such as increase in mortality should be dramatically reduced by lowering the daily dose for maintaining serum concentrations lower than $1 \mathrm{ng} / \mathrm{mL}^{64}$

In terms of AF, digoxin remains one of three drugs used for rate control in AF. Even if digoxin alone is insufficient in providing rate control during exertion in most patients, the optimal cardiac rate both at rest and at exertion is, however, still undetermined, as is the importance of achieving sufficient rate control in asymptomatic patients. Nevertheless, because of its low cost and accumulated knowledge and expertise in prescription during the last decades, digoxin probably would remain an undisputed medication for rate control AF, especially for heart failure patients.

Furthermore, it now appears that cardiac glycosides are involved in complex cell signal transduction mechanisms that may have important consequences in their application to the prevention and/or treatment of malignant diseases. . $5,66^{6}$ Patient populations with AF or heart failure are elderly and often concerned about cancer. The potential role of digoxin in this manner might be seen as a supplementary reason to be prescribed in the future.

\section{Disclosure}

The authors report no conflicts of interest in this work.

\section{References}

1. Hauptman PJ, Kelly RA. Digitalis. Circulation. 1999;99(9):1265-1270.

2. Akera T, Brody TM. The role of $\mathrm{Na}+\mathrm{K}+$-ATPase in the inotropic action of digitalis. Pharmacol Rev. 1977;29(3):187-220.

3. Wang L, Wible BA, Wan X, Ficker E. Cardiac glycosides as novel inhibitors of human ether-a-go-go-related gene channel trafficking. J Pharmacol Exp Ther. 2007;320(2):525-534.

4. Opie LH. Digitalis, yesterday and today, but not forever. Circ Cardiovasc Qual Outcomes. 2013;6(5):511-513.

5. Lloyd MA, Sandberg SM, Edwards BS. Role of renal Na+, K(+)-ATPase in the regulation of sodium excretion under normal conditions and in acute congestive heart failure. Circulation. 1992;85(5):1912-1917.

6. Ross J Jr, Waldhausen JA, Braunwald E. Studies on digitalis. I. Direct effects on peripheral vascular resistance. J Clin Invest. 1960;39:930-936.

7. Stark JJ, Sanders CA, Powell WJ Jr. Neurally mediated and direct effects of acetylstrophanthidin on canine skeletal muscle vascular resistance. Circ Res. 1972;30(3):274-282.

8. Gillis RA. Digitalis: A neuroexcitatory drug. Circulation. 1975;52(5): 739-742.

9. Gheorghiade M, Adams KF Jr, Colucci WS. Digoxin in the management of cardiovascular disorders. Circulation. 2004;109(24):2959-2964.

10. Thames MD, Miller BD, Abboud FM. Sensitization of vagal cardiopulmonary baroreflex by chronic digoxin. Am J Physiol. 1982;243(5):H815-H818.

11. Quest JA, Gillis RA. Effect of digitalis on carotid sinus baroreceptor activity. Circ Res. 1974;35:247-255.
12. Wang W, Chen JS, Zucker IH. Carotid sinus baroreceptor sensitivity in experimental heart failure. Circulation. 1990;81(6):1959-1966.

13. Ferrari A, Gregorini L, Ferrari MC, Preti L, Mancia G. Digitalis and baroreceptor reflexes in man. Circulation. 1981;63(2):279-285.

14. Krum H, Bigger JT Jr, Goldsmith RL, Packer M. Effect of long-term digoxin therapy on autonomic function in patients with chronic heart failure. J Am Coll Cardiol. 1995;25(2):289-294.

15. Kosowsky BD, Haft JI, Lau SH, Stein E, Damato AN. The effects of digitalis on atrioventricular conduction in man. Am Heart J. 1968;75(6):736-742.

16. Meijler FL. An "account" of digitalis and atrial fibrillation. J Am Coll Cardiol. 1985;5(5 Suppl A):60A-68A.

17. Riaz K, Forker AD. Digoxin use in congestive heart failure. Current status. Drugs. 1998;55(6):747-758.

18. Uretsky BF, Young JB, Shahidi FE, Yellen LG, Harrison MC, Jolly MK. Randomized study assessing the effect of digoxin withdrawal in patients with mild to moderate chronic congestive heart failure: results of the PROVED trial. PROVED Investigative Group. J Am Coll Cardiol. 1993;22(4):955-962.

19. Packer M, Gheorghiade M, Young JB, et al. Withdrawal of digoxin from patients with chronic heart failure treated with angiotensin-convertingenzyme inhibitors. RADIANCE Study. NEngl J Med. 1993;329(1):1-7.

20. Digitalis Investigation Group. The effect of digoxin on mortality and morbidity in patients with heart failure. $N$ Engl J Med. 1997;336(8): 525-533.

21. Gheorghiade M, Patel K, Filippatos G, et al. Effect of oral digoxin in high-risk heart failure patients: a pre-specified subgroup analysis of the DIG trial. Eur J Heart Fail. 2013;15(5):551-559.

22. Testani JM, Brisco MA, Tang WH, et al. Potential effects of digoxin on long-term renal and clinical outcomes in chronic heart failure. J Card Fail. 2013;19(5):295-302.

23. Rathore SS, Wang Y, Krumholz HM. Sex-based differences in the effect of digoxin for the treatment of heart failure. $N \mathrm{Engl} \mathrm{J} \mathrm{Med}$. 2002;347(18):1403-1411.

24. Ahmed A, Rich MW, Love TE, et al. Digoxin and reduction in mortality and hospitalization in heart failure: a comprehensive post hoc analysis of the DIG trial. Eur Heart J. 2006;27(2):178-186.

25. Eberhardt RT, Frishman WH, Landau A, et al. J Am Coll Cardiol. 1994;(Suppl A):A 100.

26. Castagno D, Petrie MC, Claggett B, McMurray J. Should we SHIFT our thinking about digoxin? Observations on ivabradine and heart rate reduction in heart failure. Eur Heart J. 2012;33(9):1137-1141.

27. Flory JH, Ky B, Haynes K, et al. Observational cohort study of the safety of digoxin use in women with heart failure. BMJ Open. 2012;2(2):e000888.

28. Andrey JL, Romero S, García-Egido A, et al. Mortality and morbidity of heart failure treated with digoxin. A propensity-matched study. Int $J$ Clin Pract. 2011;65(12):1250-1258.

29. Freeman JV, Yang J, Sung SH, Hlatky MA, Go AS. Effectiveness and safety of digoxin among contemporary adults with incident systolic heart failure. Circ Cardiovasc Qual Outcomes. 2013;6(5):525-533.

30. Lindsay SJ, Kearney MT, Prescott RJ, Fox KA, Nolan J. Digoxin and mortality in chronic heart failure. UK Heart Investigation. Lancet. 1999;354(9183):1003.

31. Ahmed A, Bourge RC, Fonarow GC, et al. Digoxin use and lower 30-day all-cause readmission for Medicare beneficiaries hospitalized for heart failure. Am J Med. 2014;127(1):61-70.

32. Moss AJ, Davis HT, Conard DL, DeCamilla JJ, Odoroff CL. Digitalis-associated cardiac mortality after myocardial infarction. Circulation. 1981;64(6):1150-1156.

33. Ryan TJ, Bailey KR, McCabe CH, et al. The effects of digitalis on survival in high-risk patients with coronary artery disease. The Coronary Artery Surgery Study (CASS). Circulation. 1983;67(4):735-742.

34. Just H, Drexler H, Taylor SH, Siegrist J, Schulgen G, Schumacher M. Captopril versus digoxin in patients with coronary artery disease and mild heart failure. A prospective, double-blind, placebo-controlled multicenter study. The CADS Study Group. Herz. 1993;18 Suppl 1:436-443. 
35. Hunt SA, Abraham WT, Chin MH, et al; American College of Cardiology Foundation; American Heart Association. 2009 Focused update incorporated into the ACC/AHA 2005 Guidelines for the Diagnosis and Management of Heart Failure in Adults A Report of the American College of Cardiology Foundation/American Heart Association Task Force on Practice Guidelines Developed in Collaboration with the International Society for Heart and Lung Transplantation. $J$ Am Coll Cardiol. 2009;53(15):e1-e90.

36. Gjesdal K, Feyzi J, Olsson SB. Digitalis: a dangerous drug in atrial fibrillation? An analysis of the SPORTIF III and V data. Heart. 2008;94(2): 191-196.

37. Hallberg P, Lindbäck J, Lindahl B, Stenestrand U, Melhus H; RIKS-HIA group. Digoxin and mortality in atrial fibrillation: a prospective cohort study. Eur J Clin Pharmacol. 2007;63(10):959-971.

38. Wyse DG, Waldo AL, DiMarco JP, et al; Atrial Fibrillation Follow-up Investigation of Rhythm Management (AFFIRM) Investigators. A comparison of rate control and rhythm control in patients with atrial fibrillation. $N$ Engl J Med. 2002;347(23):1825-1833.

39. Corley SD, Epstein AE, DiMarco JP, et al; AFFIRM Investigators. Relationships between sinus rhythm, treatment, and survival in the Atrial Fibrillation Follow-Up Investigation of Rhythm Management (AFFIRM) Study. Circulation. 2004;109(12):1509-1513.

40. Gheorghiade M, Fonarow GC, van Veldhuisen DJ, et al. Lack of evidence of increased mortality among patients with atrial fibrillation taking digoxin: findings from post hoc propensity-matched analysis of the AFFIRM trial. Eur Heart J. 2013;34(20):1489-1497.

41. Whitbeck MG, Charnigo RJ, Khairy P, et al. Increased mortality among patients taking digoxin - analysis from the AFFIRM study. Eur Heart J. 2013;34(20):1481-1488.

42. Roy D, Talajic M, Nattel S, et al; Atrial Fibrillation and Congestive Heart Failure Investigators. Rhythm control versus rate control for atrial fibrillation and heart failure. $N$ Engl J Med. 2008;358(25):2667-2677.

43. Friberg L, Hammar N, Rosenqvist M. Digoxin in atrial fibrillation: report from the Stockholm Cohort study of Atrial Fibrillation (SCAF). Heart. 2010;96(4):275-280.

44. Cully M. The dangers of digoxin in AF. Nat Rev Cardiol. 2013; 10(2):61.

45. Hsu LF, Jaïs P, Sanders P, et al. Catheter ablation for atrial fibrillation in congestive heart failure. N Engl J Med. 2004;351(23):2373-2383.

46. Heinz G, Siostrzonek P, Kreiner G, Gössinger H. Improvement in left ventricular systolic function after successful radiofrequency His bundle ablation for drug refractory, chronic atrial fibrillation and recurrent atrial flutter. Am J Cardiol. 1992;69(5):489-492.

47. Rodriguez LM, Smeets JL, Xie B, et al. Improvement in left ventricular function by ablation of atrioventricular nodal conduction in selected patients with lone atrial fibrillation. Am J Cardiol. 1993;72(15):1137-1141.

48. Lemery R, Brugada P, Cheriex E, Wellens HJ. Reversibility of tachycardia-induced left ventricular dysfunction after closed-chest catheter ablation of the atrioventricular junction for intractable atrial fibrillation. Am J Cardiol. 1987;60(16):1406-1408.

49. Rawles JM. What is meant by a "controlled" ventricular rate in atrial fibrillation? Br Heart J. 1990;63(3):157-161.

50. Atwood JE, Myers J, Sullivan M, et al. Maximal exercise testing and gas exchange in patients with chronic atrial fibrillation. J Am Coll Cardiol. 1988;11(3):508-513.

51. Fuster V, Rydén LE, Cannom DS, et al; American College of Cardiology/ American Heart Association Task Force on Practice Guidelines; European Society of Cardiology Committee for Practice Guidelines; European Heart Rhythm Association; Heart Rhythm Society. ACC/ AHA/ESC 2006 Guidelines for the Management of Patients with Atrial Fibrillation: a report of the American College of Cardiology/American Heart Association Task Force on Practice Guidelines and the European Society of Cardiology Committee for Practice Guidelines (Writing Committee to Revise the 2001 Guidelines for the Management of Patients With Atrial Fibrillation): developed in collaboration with the European Heart Rhythm Association and the Heart Rhythm Society. Circulation. 2006;114(7):e257-e354.
52. Olshansky B, Rosenfeld LE, Warner AL, et al; AFFIRM Investigators. The Atrial Fibrillation Follow-up Investigation of Rhythm Management (AFFIRM) study: approaches to control rate in atrial fibrillation. J Am Coll Cardiol. 2004;43(7):1201-1208.

53. Van Gelder IC, Hagens VE, Bosker HA, et al; Rate Control versus Electrical Cardioversion for Persistent Atrial Fibrillation Study Group. A comparison of rate control and rhythm control in patients with recurrent persistent atrial fibrillation. $N$ Engl J Med. 5, 2002;347(23): 1834-1840.

54. Van Gelder IC, Groenveld HF, Crijns HJ, et al; RACE II Investigators. Lenient versus strict rate control in patients with atrial fibrillation. N Engl J Med. 2010;362(15):1363-1373.

55. European Heart Rhythm Association; European Association for Cardio-Thoracic Surgery, Camm AJ, Kirchhof P, et al; ESC Committee for Practice Guidelines. Guidelines for the management of atrial fibrillation: the Task Force for the Management of Atrial Fibrillation of the European Society of Cardiology (ESC). Europace. 2010;12(10): $1360-1420$.

56. Fuster V, Rydén LE, Cannom DS, et al. 2011 ACCF/AHA/HRS focused updates incorporated into the ACC/AHA/ESC 2006 Guidelines for the management of patients with atrial fibrillation: a report of the American College of Cardiology Foundation/American Heart Association Task Force on Practice Guidelines developed in partnership with the European Society of Cardiology and in collaboration with the European Heart Rhythm Association and the Heart Rhythm Society. J Am Coll Cardiol. 2011;57(11):e101-e198.

57. Lip GY, Hee FL. Paroxysmal atrial fibrillation. QJM. 2001;94(12): 665-678.

58. Li-Saw-Hee FL, Lip GY. Digoxin revisited. QJM. 1998;91(4): 259-264.

59. Digoxin: serious drug interactions. Prescrire Int. 2010;19(106): $68-70$.

60. Hooymans PM, Merkus FW. Current status of cardiac glycoside drug interactions. Clin Pharm. 1985;4(4):404-413.

61. Chirinos JA, Castrellon A, Zambrano JP, et al. Digoxin use is associated with increased platelet and endothelial cell activation in patients with nonvalvular atrial fibrillation. Heart Rhythm. 2005;2(5):525-529.

62. Ahern TP, Lash TL, Sørensen HT, Pedersen L. Digoxin treatment is associated with an increased incidence of breast cancer: a populationbased case-control study. Breast Cancer Res. 2008;10(6):R102.

63. Chan KE, Lazarus JM, Hakim RM. Digoxin associates with mortality in ESRD. J Am Soc Nephrol. 2010;21(9):1550-1559.

64. Juillière Y, Selton-Suty C. Digoxin therapy: A persisting interest despite contrary winds. Arch Cardiovasc Dis. 2010;103(5):281-284.

65. Newman RA, Yang P, Pawlus AD, Block KI. Cardiac glycosides as novel cancer therapeutic agents. Mol Interv. 2008;8(1):36-49.

66. Prassas I, Diamandis EP. Novel therapeutic applications of cardiac glycosides. Nat Rev Discov. November 7, 2008;(11):926-935. 
Research Reports in Clinical Cardiology

Dovepress

\section{Publish your work in this journal}

Research Reports in Clinical Cardiology is an international, peerreviewed, open access journal publishing original research, reports, editorials, reviews and commentaries on all areas of cardiology in the clinic and laboratory. The manuscript management system is completely online and includes a very quick and fair peer-review system.

Visit http://www.dovepress.com/testimonials.php to read real quotes from published authors.

\footnotetext{
Submit your manuscript here: http://www.dovepress.com/research-reports-in-clinical-cardiology-journal
} 